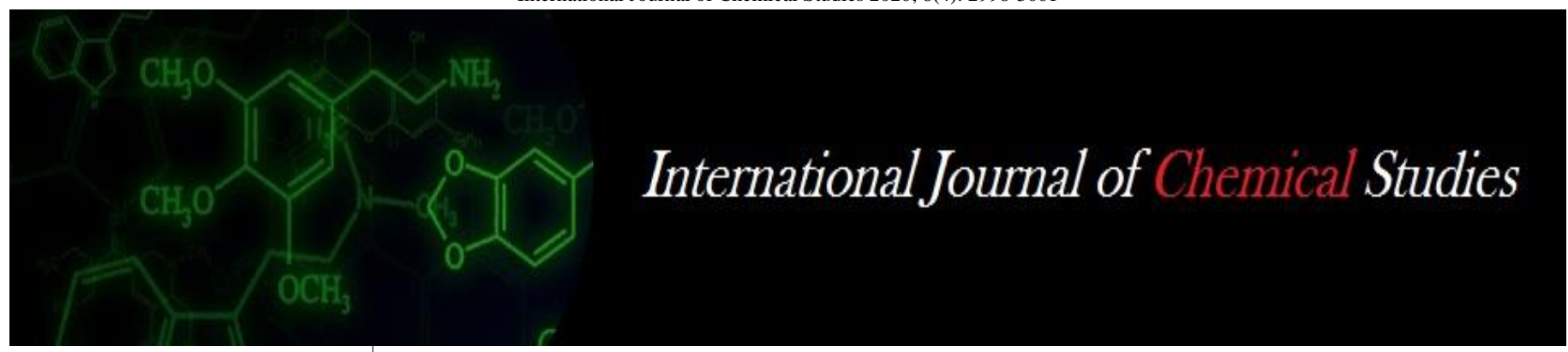

P-ISSN: 2349-8528

E-ISSN: 2321-4902

www.chemijournal.com

IJCS 2020; 8(4): 2998-3001

(C) 2020 IJCS

Received: 25-05-2020

Accepted: 27-06-2020

\section{Shabnam Ahad}

Division of Fruit Science,

Sher-e-Kashmir University of

Agricultural Sciences and

Technology of Kashmir,

Shalimar, Srinagar, Jammu and

Kashmir, India

Mohammad Maqbool Mir

Division of Fruit Science,

Sher-e-Kashmir University of

Agricultural Sciences and

Technology of Kashmir,

Shalimar, Srinagar, Jammu and

Kashmir, India

Shahida Ashraf

Division of Fruit Science,

Sher-e-Kashmir University of

Agricultural Sciences and

Technology of Kashmir,

Shalimar, Srinagar, Jammu and

Kashmir, India

\section{Sumaya Mumtaz}

Division of Fruit Science,

Sher-e-Kashmir University of

Agricultural Sciences and

Technology of Kashmir,

Shalimar, Srinagar, Jammu and

Kashmir, India

\section{Mehnigar Hamid}

Division of Fruit Science,

Sher-e-Kashmir University of

Agricultural Sciences and

Technology of Kashmir,

Shalimar, Srinagar, Jammu and

Kashmir, India

\section{Insha Majid}

Division of Fruit Science,

Sher-e-Kashmir University of

Agricultural Sciences and

Technology of Kashmir,

Shalimar, Srinagar, Jammu and

Kashmir, India

\section{Corresponding Author:}

Shabnam Ahad

Division of Fruit Science,

Sher-e-Kashmir University of

Agricultural Sciences and

Technology of Kashmir,

Shalimar, Srinagar, Jammu and

Kashmir, India

\section{Blooming behavior and pollen characteristics of exotic apple cultivars under high density planting systems of Kashmir}

\author{
Shabnam Ahad, Mohammad Maqbool Mir, Shahida Ashraf, Sumaya \\ Mumtaz, Mehnigar Hamid and Insha Majid
}

DOI: https://doi.org/10.22271/chemi.2020.v8.i4aj.10109

\begin{abstract}
The present investigation entitled "Blooming behavior and pollen characteristics of exotic apple cultivars under High Density Planting System" was undertaken at experimental fields of Division of Fruit Science, SKUAST-Kashmir, during the year 2017. The productivity of apple in Jammu and Kashmir is 12 metric tons per hectare, when it is compared with the productivity of developed nations of the world this figure is very low and there is plenty of difference in the productivity. In order to curtail this gap, eight exotic apple cultivars introduced from Holland, of uniform age namely Mitch Gala, Elrosa, Wiltons Star, Golden Delicious Reinders, Red Delicious Camspur, Red Braeburn, Jonagold A and Jonagold DC Robijin on M9T337 rootstock, were evaluated under Kashmir conditions. Blooming behavior and pollen characteristic measurements were performed on all the cultivars. Flowering characteristics revealed that earliest blooming cultivar was Red Braeburn while as Golden Delicious Reinders was the late blooming cultivar. In case of flowering duration maximum days of 13.03 was recorded in Golden Delicious Reinders while as minimum of 10.33 days in Elrosa. Maximum pollen viability $(80.80 \%)$ and pollen germination (73.38\%) was recorded in cultivar Golden Delicious Reinders while as Jonagold DC Robijin recorded minimum percentage of pollen viability $(50.30 \%)$ and pollen germination $(34.66 \%)$.
\end{abstract}

Keywords: Flowering, high density, cultivars, exotic, pollens

\section{Introduction}

Apple is the most produced fruits in temperate climate areas and is expanding into subtropical and tropical areas (Brown, 2012) ${ }^{[5]}$. Present world production of apples is close to 8, 93, 29, 179 metric tons (FAOSTAT, 2016). In India, the area under apple is 314 thousand hectares with a production of 2872 thousand metric tons and productivity of $6.98 \mathrm{M}$.T/ha (Anonymous, 2016) ${ }^{[1]}$. Jammu and Kashmir State being endowed with natural advantages of topography and climate with enormous diversity of agro-climatic conditions has immense scope for horticultural development. Horticulture industry in the state made rapid strides during the last few decades. Among the temperate fruits, apple ranks first covering 43.30 per cent area and 80.18 per cent production. Yield of apple has shown an increase from 4.12 to $12.16 \mathrm{MT} / \mathrm{ha}$ (1975-2016). The area under apple cultivation in Jammu and Kashmir state is 162.97 thousand ha with the production of 11726.83 thousand MT and productivity $10.60 \mathrm{MT} / \mathrm{ha}$ (Anonymous, 2017) ${ }^{[2]}$. Flowering in deciduous fruit trees has been an interesting subject for both growers and scientists for many years. For fruit growers, the importance of flowering lies in the fact that flowers are a prerequisite for the formation of the crop (Tromp et al. 2005) ${ }^{[15,16]}$. The amount and quality of flowers are central factors determining the size of the crop, thus representing the potential yield in the orchard. For scientists, the interest for this subject lies not only in its economic importance, but also in its complexity and significance as a crucial step of the reproductive cycle of the tree and as a model for other woody species in the Rosaceae, e.g. pears (Buban \& Faust 1982) ${ }^{[6]}$. Moreover, the study of flowering is also interesting in connection to climate and climate change, for the breeding of new cultivars adapted to different climatic regions, to understand the mechanisms of biennial bearing and for modelling the risk of attack by pests. Despite the importance of flowering for apple production and research, most of the studies in the literature have focused on solving practical problems and on later stages of flower and fruit development (Tromp et al. 2005) ${ }^{[15]}$. 
Little attention has been paid to the understanding of the different stages of the process, their timing under specific environmental conditions and their relationship to other developmental processes in the tree, such as anthesis, vegetative growth and fruit maturation (Tromp, 2005b) ${ }^{[16]}$. As apple (Malus $\times$ domestica) shows gametophytic self and cross-incompatibility, and at least two genetically distinct cultivars are necessary for stable apple production. Therefore, pollination is an important and inseparable component in respect of regular and consistent production in a fruit crop like apple, pollination is of utmost significance and its proportion and magnitude is primarily based upon appropriate selection of varieties (Chauhan et al., 2008) ${ }^{[7]}$. The viability, tube growth and morphological homogeneity related to pollen quality are the most important properties in fruit trees. These properties are useful for plant breeders, geneticists, researchers, development departments and growers (Bolat and Pirlak, 1999).

\section{Materials and Methods}

Eight exotic varieties of apple namely Mitch Gala, Elrosa, Wiltons Star, Golden Delicious Reinders, Red Delicious Camspur, Red Braeburn, Jonagold A and Jonagold DC Robijin grafted on M9-T337 rootstock were introduced by SKUAST-Kashmir from Holland in summer 2016. In order to access the performance of these exotic cultivars, it was proposed to conduct the study on their flowering and Pollen characteristics. The plant material was two year old knip boom trees planted at a spacing of $3 \times 1 \mathrm{~m}$. The experiment was laid in Randomized Complete Block Design (RCBD) with four replications and three trees per treatment as plot size. The phenological stages were observed visually when the buds started showing respective stages like date of pink bud (when the flower buds started showing pink colour at the top of its leaf scars and converted into days after reference date), date of first flower opening (when 10 per cent of flowers were open), date of full bloom (when about $80-90 \%$ of flowers were open) and date of petal fall (when $80 \%$ of flowers exhibited petal fall) was recorded (Figure 1). The duration of flowering was worked out as the period (days) between the initial bloom and petal fall in each tagged tree.

Pollen viability was tested by using triphenyl tetrazolium chloride (TTC) solution prepared by taking $1 \mathrm{~g}$ of TTC, $40 \mathrm{ml}$ of 95 per cent ethanol and the total volume was made to 100 $\mathrm{ml}$ with distilled water. Then pollens were left for 1 hour for staining and examined under microscope. Deeply stained and normal looking pollen grains were considered as viable while as shriveled and weekly stained were regarded as non-viable. Freshly dehisced pollen grains were used for in vitro pollen germination test. Sucrose 15 per cent was prepared with 0.5 per cent agar as solidifying medium and 5 ppm boric acid. Solution was placed in the petri dishes and pollen grains were dusted over it and then covered. Pollen tube growth was observed for each genotype under microscope after 24 hours of incubation period at $22 \pm 2{ }^{\circ} \mathrm{C}$. The pollen grains having pollen tube at least two times longer than pollen size were considered to be.

\section{Statistical analysis}

The observations recorded during the course of investigation were subjected to statistical analysis as per the method of 'Analysis of Variance' (Fisher, 1950). The significance and non-significance of treatment effects were judged with the help of software OP stat. The significant difference on the means was tested against the critical difference at $5 \%$ level.

\section{Results and Discussion}

Considerable variations were exhibited by the different cultivars in attaining the different flowering stages from pink bud to petal fall stage (Table 1). Pink bud stage was first noticed at 32.49 days after reference date (DARD) in the cultivar 'Red Braeburn' and last in the cultivar 'Golden Delicious Reinders' (37.74 DARD). Likewise, date of initial bloom was attained first (37.49 DARD) by 'Red Braeburn' while as 'Golden Delicious Reinders' reached this stage very late (42.80 DARD). Date of full bloom stage, was observed earliest in Red Braeburn (45.16 DARD) and late in Golden Delicious Reinders (52.16 DARD). Our results are in conformity with the findings of Pandit et al. (2017) ${ }^{[10]}$ who reported that cultivar Braeburn took 36.74 DARD to reach initial bloom and 50.59 DARD to reach full bloom. The differences in the phenological stages may be due to their genetic differences or the differential chilling requirements of these cultivars may be the reason for such variations. Furthermore these cultivars may be different in their photo sensitivity and response to temperature resulting in such variations. These results are in corroboration with the results of Gasser (1994) [8] who has reported that beginning of blooming depends highly on the site of cultivation. In the present study, the petal fall (50.16 DARD) was recorded earliest in the cultivar 'Red Braeburn' and at last (55.83 DARD) in 'Golden Delicious Reinders'. These differential results may be due to the different requirements of temperature and ecological conditions of the cultivars, as the average temperature during bloom period may affect the flowering duration.

Significant differences were observed among the various cultivars of apple with respect to flowering duration (Figure 2). The duration of flowering ranged from 10.33 days in Elrosa to13.03 days in Golden Delicious Reinders. The results are in accordance with the findings of Blazek et al. (1983) ${ }^{[3]}$ who reported 17 days of flowering duration in apples. Kumar (1996) ${ }^{[9]}$ studied duration of 10-17 days in different apple cultivars and suggested long duration to be more useful as pollinizers. According to Sharma et al. (2005) ${ }^{[14]}$ and Sharma et al. (2006) ${ }^{[15]}$, flowering duration in apple ranged from 1017 days in Himachal Pradesh.

Table 1: Flowering characteristics of exotic apple cultivars

\begin{tabular}{|c|c|c|c|c|}
\hline Cultivar & $\begin{array}{c}\text { Days taken to pink } \\
\text { bud (DARD) }\end{array}$ & $\begin{array}{c}\text { Days taken to initial } \\
\text { bloom (DARD) }\end{array}$ & $\begin{array}{c}\text { Days taken to full bloom } \\
\text { (80\%)(DARD) }\end{array}$ & $\begin{array}{c}\text { Days taken to petal } \\
\text { fall (DARD) }\end{array}$ \\
\hline Mitch Gala & 34.16 & 39.58 & 46.16 & 51.49 \\
\hline Elrosa & 36.83 & 42.49 & 47.83 & 51.49 \\
\hline Wiltons Star & 34.49 & 40.49 & 47.49 & 52.16 \\
\hline Golden Delicious Reinders & 37.74 & 42.80 & 52.16 & 55.83 \\
\hline Red Delicious Camspur & 36.83 & 41.49 & 48.83 & 53.24 \\
\hline Red Braeburn & 32.49 & 37.49 & 45.16 & 50.16 \\
\hline Jonagold A & 36.49 & 42.49 & 48.24 & 53.16 \\
\hline
\end{tabular}




\begin{tabular}{|c|c|c|c|c|}
\hline Jonagold DC Robijin & 36.83 & 42.74 & 48.16 & 53.08 \\
\hline C.D $(p \leq 0.05)$ & 0.63 & 0.86 & 0.80 & 0.57 \\
\hline
\end{tabular}

(DARD- Days after reference date), (Refrence Date; $1^{\text {st }}$ March)

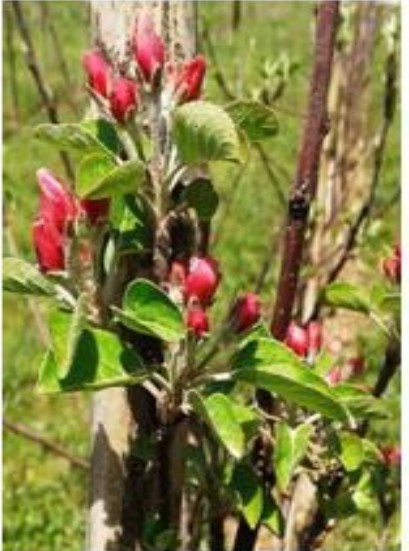

Pink bud stage

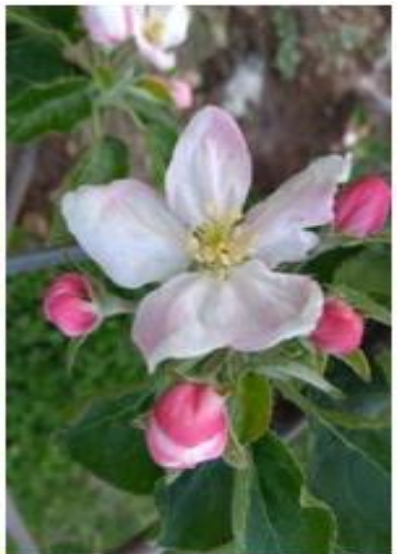

Initial Bloom stage

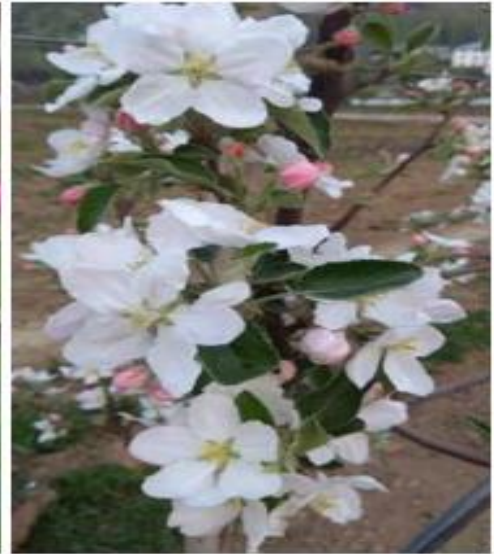

Full Bloom stage

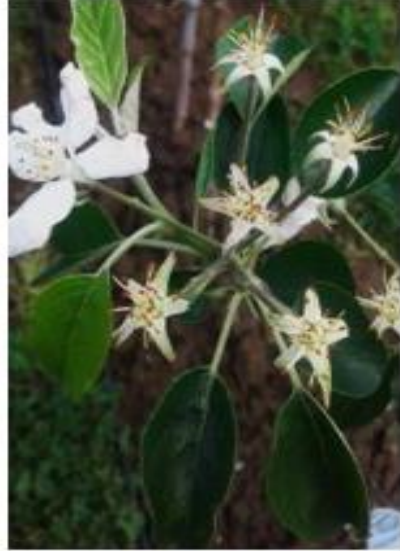

Petal fall stage

Fig 1: Flowering stages of apple

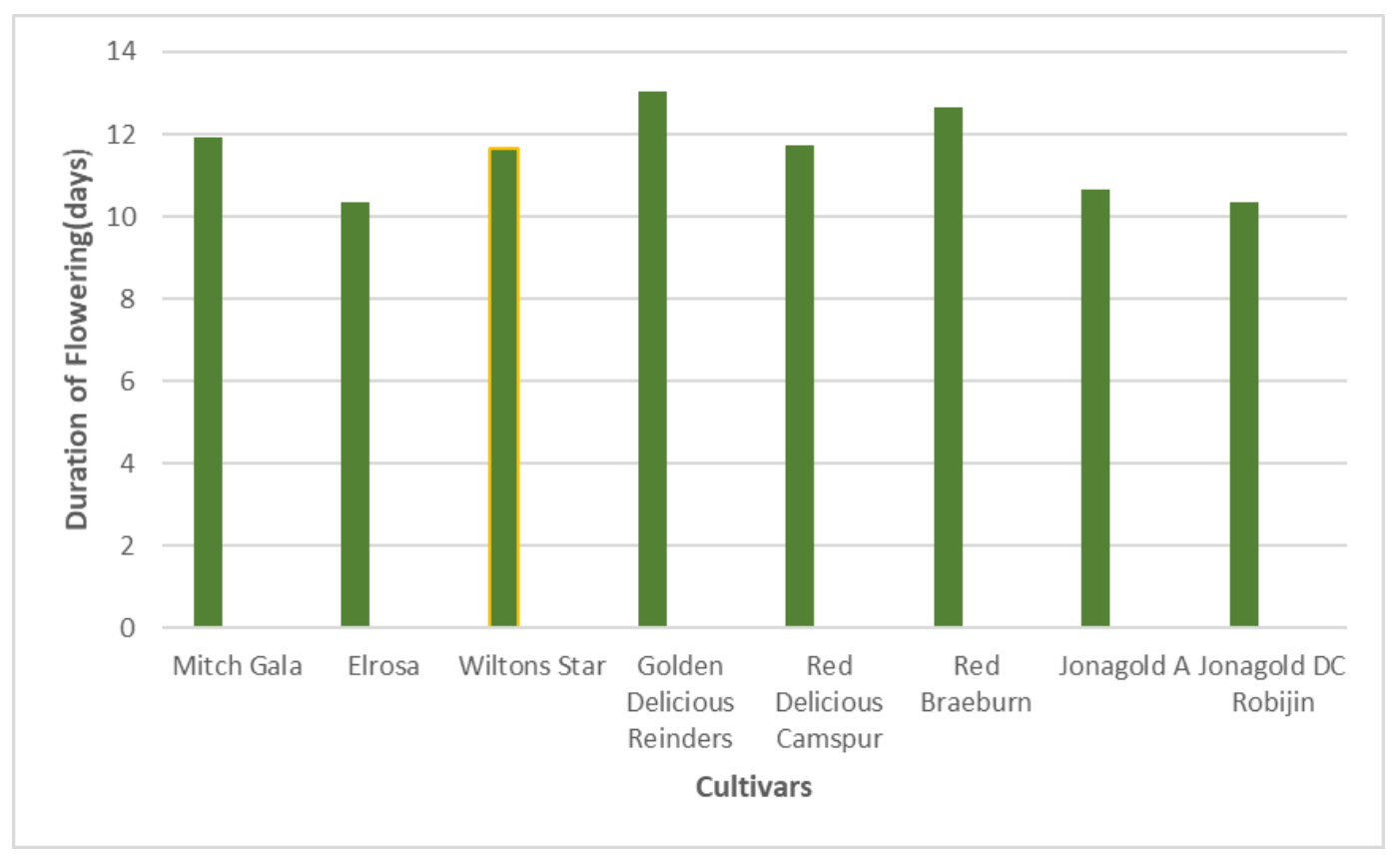

Fig 2: Flowering duration of different exotic apple cultivars

Pollen viability and germination varied significantly among the various cultivars under study (Figure 3). Among the eight varieties evaluated, highest pollen viability $(80.80 \%)$ and pollen germination $(70.85 \%)$ was recorded in cultivar Golden Delicious Reinders whereas the lowest percentage of pollen viability $(50.30 \%)$ and pollen germination $(34.66 \%)$ was recorded in Jonagold DC Robijin. Pollen viability and germination are the most important characteristics related to pollen quality and successful fertilization needs high germination rates. (Sharafi, 2011) ${ }^{[13]}$. The lower pollen viability and germination of triploid apple cultivars has been attributed to the fact that mature anthers of triploids mostly contain $90 \%$ of degenerated pollen probably due to the asymmetry in the reduction division of meiosis (Schmidt 1964) ${ }^{[12]}$. Our results are in conformity with the findings of Petrisor et al. (2012) ${ }^{[11]}$ who reported that cultivar that shows the lowest values on pollen viability and germination percentage was 'Jonagold' which is a triploid cultivar. Our results are also in agreement with Pandit et al. $(2017)^{[10]}$ who reported that highest pollen viability and pollen germination percentage was recorded in Golden Delicious. 


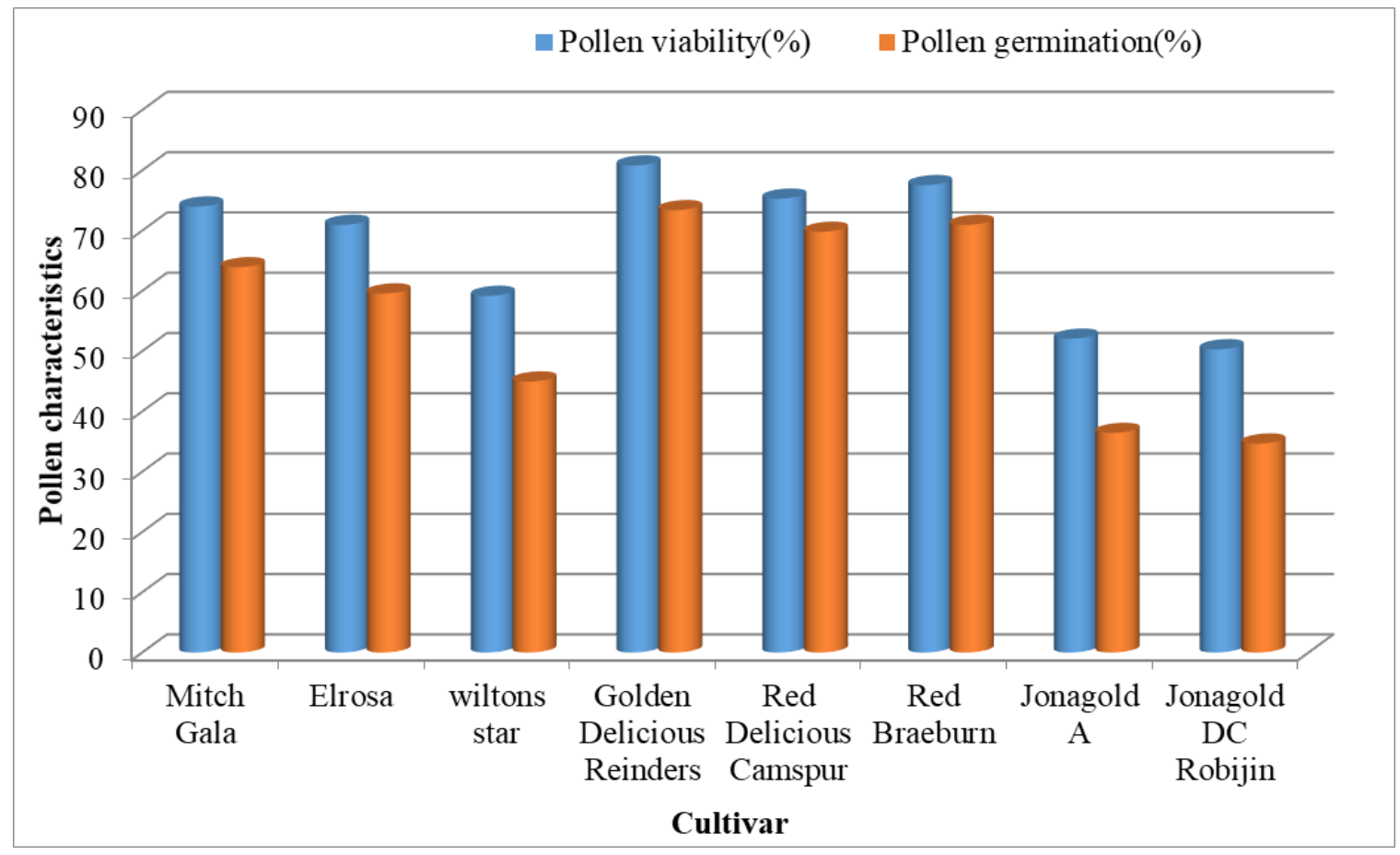

Fig 3: Pollen characteristics of exotic apple cultivars

\section{References}

1. Anonymous, All India area, production and productivity of apple. Indian Agriculture, GOI, 2016, 29.

2. Anonymous. Statement showing area, production and productivity of fruits in $\mathrm{J} \& \mathrm{~K}$ state. Department of Horticulture, Jammu and Kashmir Government, Srinagar, 2017.

3. Blazek J, Paprstein F, Kucera J. Flowering phenology of apple cultivars. Vocnarske 1983; 9:101-122.

4. Bodor P, Gaal M, Toth M. Metaxenia in apples cv. "Rewena", "Relinda", "Baujade" as influenced by scab resistant pollinizers. International Journal of Horticultural Sciences. 2008; 14(3):11-14.

5. Brown S. Apple. In: Fruit Breeding (Eds. Badenes, M. L. and Byrne, D. H.) Springer, New York, NY, USA, 2012, 329-367.

6. Buban T, Faust M. Flower bud induction in apple trees: internal control and differentiation. Horticultural Reviews. 1982; 4:174-203.

7. Chauhan G, Sharma G, Jindal KK. Studies on Flowering, Pollination and Fruit Set in Some Apple Cultivars. ENVIS Bulletin: Himalayan Ecol. 2008; 16(1):33-36.

8. Gasser H. Seit 30 Jahren der warmste Marz. Obstbau. 1994; 31(5): 155 .

9. Kumar R. Studies on hybridization in apple (Malus $\mathrm{x}$ domestica Borkh). Ph.D. Thesis, Dr. Y.S. Parmar University of Horticulture and Forestry, Nauni Solan (HP), India, 1996.

10. Pandit BA, Wani MS, Dar SA, Rashid R. Blooming behavior of exotic apple cultivars under North Himalayan region of India. xiv International Journal of Current Microbiology and Applied Sciences. 2017; 6(2):17651775.

11. Petrisor C, Mitre V, Sestras A, Sestras R. Growth and fruiting in high density apple planting system in ClujNapaco area Romania. Bulletin UASVM Horticulture. 2012; 69(1):290-296.

12. Schmidt H. Beiträge zur Züchtung apomiktischer Apfelunterlagen. Zeitschrift für Pflanzenzüchtung. 1964; 52:27-102.
13. Sharafi Y. Investigation on pollen viability and longevity in Malus pumila L., Pyrus commonis L., and Cydonia oblonga L., in vitro. Journal of Medicinal Plant Research. 2011; 5(11):2232-2236.

14. Sharma G, Anad S, Sharma OC. Floral biology and effect of pollination in apple (Malus domestica) Indian Journal of Agricultural Sciences. 2005; 75(10):667-669.

15. Sharma G, Roshan A, Sharma OC. Floral biology and effect of pollination in apple (Malus $\mathrm{x}$ domestica) Indian Journal of Agricultural Sciences. 2006; 75(10):667-669.

16. Tromp J. Dormancy. In Webster, A., Wertheim, S. \& Tromp, J. (eds) Fundamentals of temperate zone tree fruit production, The Netherlands: Backhuys. 2005a, 6573.

17. Tromp J. Flower-bud formation. In Tromp, J., Webster, A. D. \& Wertheim, S. J. (eds) Fundamentals of temperate zone tree fruit production, Leiden, The Netherlands: Backhuys, 2005b, 204-215. 